\title{
Enhancing the Quality of Tourism Communication: The Effec- tiveness of Inquiry Strategies in Intercultural Contexts
}

\author{
A. R. Roswati ${ }^{1 *}$, M. Noor Rohana ${ }^{1}$, I. Radhiah ${ }^{1}$, C. A. Nurul Ain ${ }^{1}$, Z. Rosdi $^{1}$, M. Roslina ${ }^{2}$ \\ ${ }^{I}$ Centre of Liberal and Fundamental Studies, University Malaysia Terengganu, Terengganu, Malaysia \\ ${ }^{2}$ Faculty of Modern Languages and Communication, University Putra Malaysia, Selangor, Malaysia \\ *Corresponding authorE-mail: roswati@umt.edu.my
}

\begin{abstract}
Inquiry is one of the activities that take place during conversation throughout our daily lives. It has been said that the knowledge that is obtained by an individual start by asking questions. Furthermore, inquiry is identified as an effective communication strategy which is able to influence learning and which is also able to deliver the content of learning. This leads to an increased level of achievement by a learner. However, in reality, a strategy of inquiry does not only focus on the context of communication learning but it also plays an important role in other domains of social communication. Thus, this paper discusses the aspect of mindfulness which outlines the strategy of inquiry to increase the effectiveness of communication between a tour guide and the targeted tourists in the tourism industry during tour visits. The mindfulness aspect of this research is based on the Cross-Cultural Mindfulness Model. It is important to emphasise the mindfulness aspect of inquiry strategies, so that any cross cultural communication will not create conflicts or cultural contradictions. Furthermore, it can assist in smoothing a tour session while increasing the quality of communication in tourism.
\end{abstract}

Keywords: Communication strategy; Strategy of inquiry; Tour session; Tour guide; Mindfulness model.

\section{Introduction}

WFTGA [14] defines a tour guide (TG) as an individual who provides tour services to tourists in their preferred language. A TG will translate the cultural and natural heritage of an area and will usually have special qualifications related to that location which are recognised by the authorities in the tourism industry. For tourists, using a TG service not only provides them with explanations and guidance regarding sightseeing during their trip but a TG service will also become an intermediary interacting with the society of the host country. Tourists using a TG service are also able to acquire new experiences from foreign cultures quickly and can avoid any difficulty in interacting whilst in a foreign country [13]. Therefore, one of the communication strategies to be highlighted in this paper, which underlies the effective communication between cultures, is the enquiry strategy used by TGs. This paper can be used in the future as an important reference for TGs to ensure that the questions raised by TGs do not conflict in terms of culture, ethics, dissatisfaction and embarrassment arising from the collision of cultures during a tourism trip.

Inquiry requires an appropriate selection of questioning structures and a suitable context for its use. Besides, the context of a tour session requires some adjustment and adaptation by a TG concerning the culture of the targeted tourist. Therefore, should the TG address the exact questions asked by the tourists? and will the tourists respond by giving feedback when asked questions?

It is important for a TG to have the knowledge and ability to inquire in order to communicate with the targeted tourists. In fact, they should have the ability to speak the correct language in terms of the language and culture of the targeted tourists. This will avoid any contradictions in terms of meaning, cultural values, ethics and dissatisfaction that can be embarrassing as a result of cultural clashes during communication. In [10] reviewed the necessity for a TG to know the cultural pattern of the language of the targeted tourists. This issue is fundamental to this research as it relates to the inquiry strategy. Without such knowledge, someone who is not a native speaker could misrepresent themselves and this may lead to misunderstandings.

Therefore, the main goal of this study is to discuss the aspect of mindfulness which outlines the strategy of inquiry by TGs in increasing their effectiveness during tour sessions.

\section{Literature Review}

There has been, until the present day, much research related to the discourse of inquiry, however, this has mostly been in the context of inquiry as one of the strategies of learning.

Indirectly inquiry will involve students to participate in any discussion. A research study [3] was about mathematics learning at the higher education level, recommended that mathematical learning should be conducted by using the concept of investigation or research involving a number of questions being asked. By applying this method of learning, the learning activity will enhance the understanding of the students through various activities and in accordance with the students' academic needs. Learning activities will commence by looking into the problem statements and the students will try to use various theories to solve the problems. The results will spark curiosity and will encourage the advent of new ideas.

In [14] studied inquiry in the learning of the Malay language. The aspects studied concerned the frequency of the questions that were asked in the teaching and learning (T\&L) session, the cognitive level of the questions and the components of the inquiring skills within the question circles. The findings of the study found that 
the method of inquiry was still at the low and medium level. The aspects of the question circles were focused more on individuals and society compared to countries and the world.

Studies that have examined the discourse of inquiry in social communication are rather few, one of these studies by [5] examined inquiry in terms of service at a counter. Although it was undertaken more than four decades ago, the study is still highly relevant as a base of generalised reference for inquiry in the context of social communication.

Moreover, the latest study detailing inquiry strategies in the context of social communication is the research carried out by research [9]. Their study detailed the category and function of inquiry strategies proposed by Japanese-speaking Malaysian TGs while conducting tours participated in by Japanese tourists visiting Malaysia. The study listed seven categories of inquiries asked by the tourists. There was no clear use of the categories and functions of inquiry that conflicted with the Japanese tourists' culture or which may have led to conflicts.

\section{Strategy of Inquiring in Communication During a Tour Session}

In a similar way to formal education, communication during a tour session is also conceptualised as T\&L that requires the understanding of information about tourist destinations and the TG is referred to as a teacher. If there are no questions, then, as claimed by [3], the tour session will be considered arid and the smoothness of the visit will be challenged. However, since learning during a tour session is not measured by examinations or tests at the end of the session, the learning is oriented to gain general knowledge. Furthermore, any questions associated with social communication are also included in such a tour session.

In addition, inquiry strategies are applied differently according to the questions asked in education and social communication because they involve a cross cultural context. Research on the tourism industry depicts a TG as a mediator, a middle man or a cultural broker while in China they are called 'country windows' [2] where a 'country window' serves as a cultural interface to interpret a host country's culture to the tourists. In playing this role, intercultural communication will take place. According to [11], there are four issues that arise during intercultural communication. First, at least two people or two groups are involved. Second, the situation is surrounded by different cultures. Third, involves the context of the interaction and fourth, both parties are trying to understand each other.

In [1] noted that in casual or business communication, being sensitive or intent, or considering intercultural factors was the key that ensured that communication between cultures was successful. In that case, the aspect of mindfulness or 'taking in to consideration' must be present in intercultural communication as it relates to the management of sharing the meaning of the content that is suitable and effective in achieving the desired goals [11]. Mindfulness was described as a process of seeing a new difference [4]. Seeing a difference actively keeps us always at the forefront. This will ensure that we are sensitive to the environment of others, open to new information, able to see things from different perspectives and our sensitivity can be enhanced from various perspectives in problem solving.

\section{Mindfulness Aspects in the Application of Inquiry Strategies During a Tour Session}

Cross-Cultural Communication Mindfulness Model by [11] which comprises the components, criteria and outcomes that underline one's needs through the exchange, transfer, management and intermediation of cultures through verbal or non-verbal language and space whilst intercultural communication takes place. This model serves as the basis for applying the inquiry strategies by
TGs to tourists throughout a tour session in a cross-cultural context.

\subsection{Knowledge Factor}

Based on this model, the knowledge factor refers to an individual's deep understanding of certain phenomena within the information derived from learning, experience and observation. In order to manage the cultural differences prudently, one should take into consideration the cultural membership and personal identity factors of others. The knowledge factor is based on seven factors, namely culture/personal values, verbal communication, non-verbal communication, the inner and outer boundaries of a group, building relationships, conflict management and intercultural adaptation. To enhance knowledge, one must be aware of what is taking place in the mind, feelings and experience of others [7].

The concept of mindfulness is an effective first step in raising the awareness of our thinking system and judgments. Through this mindfulness, we will be more sensitive to the similarities and differences that exist between individuals in different groups.

Therefore, in the context of an inquiry strategy, a TG should have knowledge about the cultural background of the targeted tourists. A mastery of the targeted tourist's culture will make the TGs task easier and more effective in managing the differences and similarities between the host country and the tourist's culture. This should ensure that any inquiry that may be in conflict with the relevant culture can be avoided.

For example, Japanese tourists are noted for snapping photos during tours which are known as kinen shashin or pictorial memories [6-8]. Therefore, a TG should ask whether tourists need time to take pictures or whether they would like to take pictures at a location. Alternatively, they should avoid asking about marital status as this is inappropriate in Japanese society. Asking Muslim tourists about halal food and beverages may also be deemed as sensitive.

In conclusion, concerns over the knowledge factor must be present indirectly during the adaptation process of the tourist's culture which will result in reinforcing the ties between a TG and their tourist's group.

\subsection{Motivational Factors}

Motivational factors refer to one's willingness to learn something other than their culture and interact with people of different cultures. The motivational factor in this context is seen as an identity management issue that includes identity domain (Identity: cultural identity, ethnicity, gender and personal and situation identity: role identity, relationship, professional and interaction symbols) and the issue of identity requirements (safety, participation, trust, relevance / relationship and stability) [11].

In the event of intercultural clashes, main identity and situation identity will interact with each other and influence the communication process between cultures. While identity needs will be influenced by cultural membership and the personal factors of an individual. We need to systematically analyse the needs of our identity and those of others in the event of cultural clashes. We have to adapt to the identity of the domain and its value that will affect our interactions with people of different cultures [7].

Therefore, a focus on the needs of an individual's identity at both the group community-based and the individual community-based levels should be emphasised when intercultural communication is taking place. It is also necessary to look at the ethnocentric tendencies that are brought along when an intercultural situation occurs. This is because built in ethnocentric standards tend to be used by humans especially in evaluating people of different cultures.

In the context of an inquiry strategy based on the mindfulness factors, a TG should coordinate their identity as a host citizen which embraces a religion, belonging to a particular culture or a 
certain ethnicity that is outlined as domain identity. While the identity needs to be in the context of the visit as the leader of the tour, information disseminator, ambassador for the host country, tourist protector and should also be sensitive to the identity carried by the tourists.

This is in line with the findings by [9] where the applied inquiry categories were to get information, being mindful and to get consent between the categories of inquiries that were asked to the Japanese tourists during a tour. This was based on the identity needs carried by a TG as the leader of the tour. However, the identity of the TG depended on the particular environments they were in. When a TG was in his own culture, the identity of this requirement was not important when interacting with people who did not belong to the group.

\subsection{Skill Factors}

Skill factor in this model refers to the ability to integrate knowledge factors and motivational factors effectively and appropriately during inter-cultural communication. Adopting interaction skills such as observation, listening, empathy via verbal skills, nonverbal-sensitive skills, stereotype skills and the ability to deconstructing conflicts will help prudent interaction in inter-cultural situations.

In the context of an inquiry strategy based on the mindfulness factor, the identity of the domain that goes beyond the knowledge possessed by TGs, the identity of the tourists and the identity needs that arise as a result of the cultural collision of both parties in the tour visit can enforce prudent inquiries.

The three factors that underlie the components in this model, which are knowledge factors, motivational factors and skill factors will interact with one another during an intercultural communication. When one interacts with people of different cultures, there will be a signal to their thoughts about the details of those different cultures. The element of trust, openness to accept and the affiliation of both parties will be established when one acknowledges the existence of differences between them and their different cultures.

When a combination of these three factors is arranged, it will produce the criteria of suitability, effectiveness and create communication-based on a level of satisfaction between two parties. As a result, both parties will feel that they are being respected, their presence is mutually accepted and understood in the context of the application of an inquiry strategy. This mindfulness model is a comprehensive picture, where one needs to consider certain factors when communicating with people of different cultures. These factors are the communication competencies between cultures that must be complemented by individuals to ensure effective and appropriate communication in an intercultural context.

Thus, this model is suitable to address the necessities of mindfulness that should be incorporated when inquiring.

\section{Conclusion}

It is important that questions by TGs must be well designed and for them to know the purpose, function and type or category of inquiry in order to achieve the goal of communication in a tour session. In addition, according to research ${ }^{7}$, most of the time, a TG will only provide a brief explanation and clarification continuously from the start of a tour session. Therefore, it will become necessary for the TG when playing their role as a guide not only to explain but also to incorporate other various strategies to diversify their delivery pattern during a tour visit. This paper explains in detail the aspects of mindfulness underlying the application of inquiry strategies by a TG during a tour session. Applying a suitable and appropriate strategy of asking questions or inquiring will further enhance the effectiveness of a TG's communication with the targeted tourists.
Overall, this study has shown the importance that should be given when applying inquiry strategies in the communication between cultures by TGs. The researcher hopes that this paper will become a reference and a platform for the exploration of the application of inquiry strategies based on the use of the real-data of interactions during tour sessions supported by the interviewing techniques. As a result of the exploration of intercultural communication in a reallife situation, it was hoped to produce a model of mindfulness based on the reference of inquiry strategy application according to the culture of a particular tourist community.

\section{References}

[1] Gudykunst WB, Kim YY. Communicating with strangers. McGraw-Hill, 2003.

[2] Huang Y. Identity negotiation in relation to context of communication. Theory and Practice in Language Studies, 2011, 1(3): 219-225.

[3] Krismanto A. Some techniques, models, and strategies in mathematics learning. Depdiknas Dirjen Pendidikan Dasar dan Menengah, 2003

[4] Langer EJ, Moldoveanu M. The construct of mindfulness. Journal of Social Issues, 2000, 56(1): 1-9.

[5] Merritt M. On uestions following questions in service encounters. Language in Society, 1976, 5(3): 315-357.

[6] Mok C, Lam T. Travel-related behavior of Japanese leisure tourists: A review and discussion. Journal of Travel and Tourism Marketing, 2000, 9(1-2): 171-184.

[7] Ong LT. An Analysis of the communicative acts of tour guides at the workplace. Dewan Bahasa dan Pustaka, 2005, 5(4): 109-147.

[8] Pizam A, Jansen-Verbeke M. Are all tourists alike, regardless of nationality? Journal of International Hospitality, Leisure and Tourism Management, 1997, 1(1): 19-38.

[9] Roswati AR, Mazlina A, Roslina M, Nor AA. Inquiry strategies in Japanese language communication during tour guide session. Universiti Putra Malaysia, 2018.

[10] Tanaka N. Politeness: Some problems for Japanese speakers of English. JALT Journal, 1988, 9(2): 81-102.

[11] Ting-Toomey S. Communicating across cultures. Guilford Press, 1999

[12] World Federation of Tourist Guide Association (WFTGA). Definition of tourist guide. WFTGA, 2011.

[13] $\mathrm{Yu} \mathrm{X}$, Weiler B, Ham S. Intercultural communication and mediation: A framework for analysing the intercultural competence of Chinese tour guides. Journal of Vacation Marketing, 2002, 8(1): 75-87.

[14] Zamri M, Nor RL. Oral question approach in teaching by Malay language teachers: Observation methode. Jurnal Pendidikan Bahasa Melayu, 2011, 1(1): 51-65. 